Journal of Education and Educational Development

8(2), 398-417, 2021

DOI: http://dx.doi.org/10.22555/joeed.v8i2.41

\title{
Academic Resilience: The Ultimate Thriving Constituent Towards Persistence in Doctoral Studies
}

\author{
Sumaira Chamadia
}

Shaheed Zulfikar Ali Bhutto Institute of Science and Technology, Pakistan

Jawaid Ahmed Qureshi

Shaheed Zulfikar Ali Bhutto Institute of Science and Technology, Pakistan

\begin{abstract}
A doctoral degree is perceived as a milestone in one's expedition of educational advancement; however, studies show that 40\% to $60 \%$ of doctoral candidates do not possess the persistence to complete their degree. The purpose of this phenomenological inquiry is to explore the factors that contribute towards increasing the persistence level among doctoral students. Semi-structured inperson interviews of eight participants (four male and four female) selected through snowball sampling were conducted in a university setting. Thematic analysis of data identified certain intrinsic motivational factors including career progression, gaining subject command, and the desire to achieve self-actualization. Autonomy, sense of purpose, self-determination, and problem-solving skills were found to be the most effective factors that promote resiliency in the students to help complete their degrees. These research findings would help the faculty and the administrators in designing an efficient recruitment program to select the candidates with a prospective potential. Further, it would help in devising the mentoring and counseling programs to develop the identified traits in the enrolled doctoral candidates to promote their retention in the doctoral program.
\end{abstract}

Keywords: academic resilience, career progression, doctoral education, initial motivation, perceived hurdles, personality traits 


\section{Introduction}

Receiving a doctoral degree is one of the most esteemed achievements in one's expedition of educational advancement; yet, few candidates can attain this rank (Mujtaba et al., 2008). Earning this revered degree is difficult because doctoral students have to strive very hard to complete their dissertations. Retention and persistence to graduation have been the focus of discussion within academia globally (Linden et al., 2013) because around 40\%-60\% of the enrolled students do not complete their graduation (Berelson, 1960; Bowen \& Rudenstine, 1992; Cochran et al., 2014). The difficulties in the journey of this academic achievement encompass quite a few challenges including extensive time demands, the laborious and concentrated research process, fulfilling the requirements to get the research work published, completing the dissertation, and ultimately, getting through the comprehensive examinations. Then the question arises: Why would an individual choose to pursue a doctorate? There is ample research demonstrating that pursuing a doctorate is a high-risk strategy (Golde, 2005). What motivates a person to commit a significant segment of one's life to struggle for a degree with minimal chances of attainment at the end (Powell \& Green, 2007).

There is little work done in the literature that sheds light on the issue of initial motivation. From their discussions with successful candidates, Churchill and Sanders (2007) find five categories of motives for embarking on a doctoral study: (a) career development, (b) dissatisfaction in the current job, (c) personal motif, (d) research as politics, and (e) drifting into the challenge. A study of business professional doctorates (Gill \& Hoppe, 2009) presented a few motivational "profiles" that could lure a candidate to pursue a doctoral study. These include (a) traditional (common purpose of further academic studies), (b) advanced (entry leading to professional development), (c) continuing development (career growth to achieve the professional advancement), (d) transition (switch to a different career), and (e) personal fulfillment (self-enhancement). The first two motives are related to the early stage careers, whereas the third and fourth motives are associated with the later stage of the professional career.

In developing countries, especially in Pakistan, there is a dearth of PhDs. This degree is associated with the greatest level of competence because it develops the requisite intellectual and analytical skills resulting from rigorous research tasks. Because this degree encompasses the extensive drill in methodology 
and statistics, the degree holders are viewed as significant contributors to the innovative advancement of developing countries. In Pakistan, 177 degree-awarding universities aim to promote research-based activities in the country; however, only $40 \%$ of these institutions have been able to produce Ph.D. scholars, resulting in the lack of doctorate human resources in the country (Halai, 2011). The statistics given by the Higher Education Commission (2005) showed that only $25 \%$ of the university faculty in Pakistan consists of doctorates. A doctorate is not only a requisite for university teaching but academic research as well. Clark (2005) states that not only is education research inevitably important in Pakistan, but it is also crucial to conduct peer-reviewed research in commensuration with international standards. Despite the dire need to produce doctorates in Pakistan, there has been little effort to identify the factors that help retain doctoral students to graduation and their transition to the professional world. There has been no research conducted in Pakistan to identify the individual characteristics that constitute the persistence and perseverance to pursue and thrive in the doctoral program. Literature indicates that faculty should be trained to mentor doctoral candidates, otherwise, their role is bridled to supervising the tasks rather than ensuring personal learning and development of the students (Linden et al., 2013).

Although the intrinsic motivational factors are necessary for the individuals to embark upon the doctoral degree, the motivation can be easily lost in the absence of academic resilience. Hence, the purpose of this study is to identify the intrinsic motivational factors which encourage doctoral candidates to pursue this difficult journey. Another aim of this study is to identify the perceived hurdles which hinder the progress of doctoral studies. Finally, we attempt to explore the personality traits that contribute to increasing the persistence level among doctoral candidates, facilitating the successful completion of their degrees despite the perceived challenges of the program. We develop a conceptual model of student persistence in doctoral studies by combining the intrinsic motivation factors highlighted in selfdevelopment theory and the four constituents presented in Benard's (2004) theory of resilience. This study could help universities to design adequate recruitment programs, devise retention models based on persistence factors and introduce mentorship programs to retain the students to graduation. 


\section{Research Questions}

1. What are the initial motivational factors which influence individuals to embark upon the doctoral degree?

2. What are the perceived hurdles that hinder the progress in the doctorate program?

3. What are the personality traits that contribute to increasing the persistence level among doctoral candidates?

\section{Literature Review}

The current doctorate curriculum differs greatly from earlier education (Castro et al., 2011) both intellectually and psychologically. Intellectually, it requires intensive research work that focuses on a particular discipline, which helps inculcate and develop analytical and reasoning skills. Psychological differences range from dealing with the time constraints and coping with frustration, stress, and boredom resulting from complicated general work processes, as doctoral students have to work independently unlike in their earlier studies. Acquiring skills in domain-specific academic writing and integrating into the doctoral cohort adds to the psychological aspects (Pyhältö et al., 2012). On the other hand, several authors investigated the psychological well-being of teachers (Akram, 2019). While preparing to embark upon the doctoral degree, one needs to self-evaluate in order to find out the internal motives to pursue the degree. Failing to adequately recognize the aspirations to pursue a doctorate may cause additional anxiety and dissatisfaction and consequently drop out while suffering from such conditions. There are certain motivational factors connected to resilience theory that are extremely significant in sustaining the urge to complete the degree.

Academic resilience has been evidenced as the capability to attain in an academic setting despite exposure to a challenging environment (Morales, 2008). McMillan and Reed (1994) argue that progressive interpersonal and idiosyncratic influences have a significant role in constructing academic resiliency. High expectations from family and/or mentor support can be counted as examples of positive interpersonal relationships. Several studies in literature favor the trait of resiliency as a thriving force behind completing doctoral studies. González (2007), in his study to find out the supportive factors among Latin doctoral students, identifies 
resilience in the students that helped in coping despite challenges in the program. Further, the ability to work independently, social integration, and sense of purpose was identified as the contributing factors, which helped them progress despite the academic complexities. Fuerth (2008) indicates that the students who thrive have strong problem-solving skills, can work independently, integrate socially, and can clarify their purpose and objectives.

Moreover, the value theory states that people's actions are driven by the motives they value. The motivating factors could be personal and professional development, career progression, recognition in society, and self-esteem, among others. The most popular theory in this regard is given by Abraham Maslow in 1943 named Maslow's Hierarchy of Needs theory (1943). The social and esteem needs contribute greatly in motivating individuals to pursue higher studies (Teowkul, et al., 2009). In addition, Herzberg's Two Factor theory presents achievement, recognition and growth, and financial benefits as two key motivational factors (Gawel, 1996).

The level of perceived emotional support, self-efficacy, and time management have emerged as key differentiating factors between the persisters and non-persisters in a study conducted across various disciplines of business administration, nursing information services, and education by Holder (2007). A study on business doctoral students by Gill and Hoppe (2009) proposed various 'profiles' that motivate the students to embark upon the doctorate. These influencing factors entail academic engagement, entry into the program to advance professional development, career advancement through professional growth or transition into a new career, and lastly, fulfillment of personal motive of self-determination. The first two motives can be categorized as an individual's early career and the other two can be associated with either the middle or later career stages. Their study adopted the case study approach to explore the insights to comprehend the motives that could have led the candidates to pursue a doctorate in 'history.' In this regard, Brailsford (2010) posits that a desire to learn the subject knowledge of their discipline and to improve their career prospects, as well as self-development, were the factors motivating candidates to pursue their doctoral study. However, the study did not reveal any self-actualization motives, and it was identified that an influence of third parties (e.g., family, friends, and academicians) had an encouraging effect on deciding to enroll in the doctorate program. These findings helped in shaping the 
recommendations for the universities to offer orientation workshops for potential candidates to get the gist of their intrinsic motives to help them in their progression before they enroll in the program. Hymes et al., (2015) examined the factors of motivation and consequently, the reaction to decide to and embark upon the doctoral degree in the context of a midlife career change. They took the phenomenological approach to understand the phenomenon of midcourse life corrections and found that participants who opted for the degree were the candidates who wanted a career change, whereas the rest wanted to increase their knowledge in the specific field of work. The "do-overs" were considered by the people who had missed the attractive opportunities in life because of financial deficit, fear, or lack of confidence; others opted for the doctoral studies because they were dissatisfied with their current jobs and wanted to construct a new future for themselves. Despite several responses of regret and even trauma, the majority of responses exhibited the feeling of satisfaction in going for midcourse correction by pursuing a doctoral education.

The personal, professional, social, and institutional factors also have an immense effect on the degree completion despite having adverse situations and challenges in the education path (Spaulding \& Szapkiw, 2012). Many doctoral scholars pursue a doctorate program for the sake of their professional development (Burton, 2020). In this context, Dickerson et al., (2014) show five themes that are believed to cope with the challenges faced in the program: (a) compartmentalization of life, (b) outside support systems, (c) justification for participation in the program, (d) emotional status, and (e) structure of the program.

\section{Social/Psychological Theory}

The theoretical framework of this study and its research findings are organized within the framework of the self-determination theory (SDT) by Deci and Ryan (1985) and Benard's (2004) theory of resilience. The SDT theory posits that intrinsic motivation entails engaging in various activities to achieve the satisfaction inherent in performing those activities and by receiving their corresponding rewards. According to Deci and Ryan (1985), these rewards include the feeling of autonomy, competence, and relatedness needs which act as a fuel to perform those activities to satisfy one's innate needs (Grolnick et al., 2001). Autonomy has been emphasized as the primary psychological need which is achieved by the sense of wellbeing and independence to pursue the actions of one's choice. Competence, on the other hand, is related to a sense of accomplishment which is achieved by having confidence in 
an individual's ability in accomplishing a task. Relatedness refers to the sense of belongingness and connectedness with other individuals (Garcia, 2014). SDT posits that these intrinsic motivation factors are crucial for an individual's psychological wellbeing (Moreno \& Kollanus, 2013), and the individuals lacking these factors are less likely to complete their dissertations (Garcia, 2014).

The literature on doctoral studies has proved several challenges that impede the completion of the doctoral degree and increase the rate of attrition among doctoral students. The complications faced in general work processes, difficulties in domain-specific academic writing (e.g., problems in phrasing the research questions or building a conceptual framework), and uncertainty of work completion because of the dependence on supervisors and the scholars' community are the main problems identified in the previous studies. In this context, resilience theory helps explain the coping and survival strategies in the education path of the participants. The resiliency model can be described as a form of academic understanding and problem-solving that focuses on the positive attributes and strengths of people and systems instead of the insufficiencies. It identifies the personal traits necessary to cope up with the challenges of a doctoral study program.

\section{Resilience Theory}

Masten and Coatsworth (1998) stated that resilience is a normative system of humans beings accustomed to their environment in any circumstance. It is strengthened by problem-solving skills which involve logical and analytical thinking, and the ability to plan and develop insight. This could also be referred to as 'good intellectual functioning', Alva and Padilla (1995) defined resilience as the process that allows students to minimize the risks at school by overcoming the hurdles and excel in academics. Resilience, in general, is defined as the process of, capacity for, or outcome of successful adaptation despite challenging or threatening circumstances (Howard \& Johnson, 2000). However, resilience in the academic context can be defined as the students' ability to deal effectively with academic setbacks, stress, and study pressure.

Benard proposed four constituents of resiliency theory that are related to this study: (a) social competence, (b) problem-solving, (c) autonomy, and (d) sense of purpose. Social competence is an attribute and skill to socially integrate oneself to the community around and positively adapt to any kind of situation 
with perseverance. Problem-solving involves an individual's capability to think critically and analyze logically to extricate situational circumstances. Sense of purpose determines setting clear objectives and goals and sets the direction and strategy accordingly. Autonomy refers to the person's ability to perform one's tasks independently and remain assertive in adverse situations. It also entails the selfconfidence to feel control over one's environment. People who have a sense of purpose have meaning in life and set goals. They can raise a unique voice to attain and accomplish their purpose.

\section{Methodology}

The qualitative approach situated in the social constructivism paradigm is required in this research to explore and understand a central phenomenon to answer the research question related to the motives, aspirations, and challenges of doctoral students. Phenomenological inquiry is used to understand the lived experiences of the doctoral students in tertiary educational institutions, it is required to interpret the meaning of those experiences that could be unknown to the person who is living through them and then to explain the captured thematic analysis through a comprehensive account (Bashir et al., 2017; Cresswell, 2007).

\section{Participants}

Participants were eight doctoral students who have completed their coursework at a private university located in Karachi, Pakistan, and are working on their dissertations. We chose a small sample size because we attempt to conduct an in-depth case-oriented analysis. After completing the five interviews we started getting a homogenous set of information from each additional participant and the phenomenon of our interest (resilience) was addressed and hence we stopped taking interviews after the eighth participant because we reached the saturation point of data collection. While choosing the participants, care was taken for the composition of the members so that the research could completely reflect the experiences of the students covering a range of demographic factors. In this research study, 50\% $(n=4)$ of the participants were males and 50\% $(n=4)$ were females. All were categorized in the age bracket of 25-45 years. Three of the participants belonged to the faculty of the university and the rest were working in the corporate sector or other academic institutions. A matrix of participants' composition is provided in table 1 . 


\section{Table 1}

Matrix of Participants

\begin{tabular}{llll}
\hline Participant & Gender & Age bracket & Professional affiliation \\
\hline Participant 1 & Female & $25-35$ & Academics \\
Participant 2 & Female & $25-35$ & Academics \\
Participant 3 & Female & $25-35$ & Academics (non faculty) \\
Participant 4 & Female & $25-35$ & Academics (non faculty) \\
Participant 5 & Male & $35-45$ & Academics \\
Participant 6 & Male & $35-45$ & Public service \\
Participant 7 & Male & $25-35$ & Corporate \\
Participant 8 & Male & $25-35$ & Corporate \\
\hline
\end{tabular}

\section{Sampling}

Participants were doctoral students who had completed their coursework and were working on their dissertations. Many doctoral students enrolled in the Phd program of a private university were selected using snowball sampling but only those participants were recruited who were willing to participate in the study. This method is defined as sampling that "identifies cases of interest from people who know people who know which cases possess rich information" (Marshall \& Rossman, 1999, p. 78).

\section{Data Collection}

The mode for gathering data was in-person interviews accompanied by the corresponding notes. An interview protocol was developed to glean out the essence of the lived experiences of the participants. The research-guiding questions were used to determine the motivation behind pursuing the doctoral degree and the personality traits that can affect students' persistence levels in their pursuit of the degree. Each doctoral student was provided with the overall view of the research study and the complete disclosure of all the risks associated with the study. Interviews were conducted in a private university located in Karachi with the participants' consent.

\section{Instrument}

The instrument used for the research study was a brief demographic 
questionnaire and a semi-structured interview. The demographic questionnaire collected data regarding the participants' academic background, family background (marital status, etc), age, and career plans. The questionnaire was followed by a semi-structured, predefined set of questions in an interview protocol that was developed in light of the literature review covering the challenges and hurdles in the doctoral educational path as well as the personality traits that help a candidate persist to complete his or her degree. Interviews were conducted, audio-recorded, and transcribed in verbatim form by the first author. The interview responses were analyzed through open coding to carefully identify the various themes emerging from their experiences. The interviews were informally conducted in the classes (and offices, in the case of faculty members) with minimal distractions. The participants were interviewed only once and half of the participants were contacted a second time for member checking only.

\section{Reliability and Validity}

Since the researcher is actively participating in close contact with the research participants and cannot take a detached view, qualitative research needs to be conducted prudently to preclude the possibility of casting the researcher's beliefs on the interviewee (Chamadia \& Shahid, 2018). Reliability was dealt with by the member check of the data, that is, after the transcription of each interview, the hardcopy of the findings was sent to the participants to verify if the content extracted from the interview was the same as was provided. Fifty percent of the participants were asked to review the findings to check whether the meanings drawn out from their experiences were accurate. All participants could not be approached due to time and location constraints during the data analysis process. The participants were chosen from a blind selection to review the findings and implications. These canons were based on Hatch's (2002) claim prescribed method that participants should have the chance to consider and give their reactions to the interpretations included in the summary. The depth of pertinent literature and suitable research design assured the credibility of this probe. Eventually, corresponding findings with pertinent studies ensure trustworthiness and triangulation of data and findings (Bashir et al., 2017). 


\section{Findings}

The repeated ideas from different participants during the interviews were sought to identify the emerging categories. After comparing and ranking different categories, various themes and patterns were identified according to the significance and related to the research questions.

\section{Thematic Analysis}

Several themes emerged while collecting responses from participants regarding the motivation to embark upon this challenging environment, the perceived hurdles of the doctorate program, the personality traits which contribute towards persistence, and the suggestions for the educators. Descriptions of the themes and their corresponding responses follow.

\section{Initial Motivational Factors}

The most common theme that emerged in all the participants' responses was the requirement of a doctorate in the job market, especially in the academic field, for career advancement. While describing her initial motivation to pursue a doctorate, Participant 1 explained:

"The sole motivation from beginning till the end was the career progression. The promotion for the next level is not possible until the requirement of the doctorate is met. In the academic field, a doctorate is essential. I don't want to remain an assistant professor throughout my life."

Participant 2 described her sole motivation to study:

"In the academic industry, you will remain as an assistant professor throughout your life if you do not attain the doctoral degree. It's an essential step towards becoming a professor which I aspire to be."

It is evident from their statements that a doctorate is important for career progression.

Subject command emerged as another significant theme while inquiring about the initial motivation of the participants. It also appeared as one of the 
significant factors for keeping students' persistence levels high while continuing this challenging educational program. Participant 3 described her motivation to pursue her doctorate:

"I have always been fascinated by market research and want to get the expertise in the field. Throughout my doctorate courses, I have been learning to apply the techniques of data analysis, which has helped me in achieving proficiency in my current work. I want to learn more and more innovative techniques to be able to do my work more efficiently."

Participant 5 expressed his reasoning to pursue his doctorate:

"I never wanted to do a doctorate but it's a career requirement. It is the need of an hour because if you want to continue with the faculty career it's necessary to keep oneself updated with the latest developments in the field to deliver the best to thestudents. So basically it's the requirement to get the command on the subject."

Another theme that emerged during the interviews was the need for acceptance, reverence, recognition, and self-esteem in society. The nonverbal gestures of the participants indicated their feelings of pride because there are very few people who embark upon this terminal degree. This can be referred to as selfactualization.

Participant 2 said:

"There is not a single female doctorate in her family and she wanted to be the forerunner in earning this degree."

Participant 6 also seemed influenced by this trait, as he stated:

"Initially when I started my career I was placed in a very congested office, I was so uncomfortable working there. I wanted to have an elegant and comfortable working environment. I had an urge to get more respect, recognition, and monetary benefits." 


\section{Perceived Hurdles That Hinder the Progress}

Around $60 \%$ of the participants were whining about the inaccessibility of supervisors and the unavailability of timely and adequate guidance during their research projects. Further, there is an unreasonable amount of workload in the form of assignments, and quizzes which compel the students to compromise on quality. Lack of liaison between the industry and academia also poses a hindrance in recognizing the true potential of a doctorate. The missing association between the industry and the academic institutions has also been highlighted by Chamadia and Shahid (2018). Other troublesome issues included: limited choice of courses offered in the desired domain because of unavailability of professors with expertise in a particular field. Moreover, maintaining a balance between the workload and the educational requirements also poses one of the toughest challenges for working students.

While describing the frustrations during his journey of doctorate education participant 7 said:

"The most frustrating part of my Ph.D. was the unavailability of my supervisors when I desperately needed them."

\section{Personality Traits}

Several positive individual characteristics have influenced the participants to be resilient in the educational path of the doctoral program (see Figure 1). These traits included self-determination, self-reliance, problem-solving, autonomy, and sense of purpose. The latter three are components of Benard's (2004) theory of resilience.

The most eminent theme that emerged out of every participant's response was self-determination. It refers to an individual's perseverance in adverse circumstances; it's a positive emotional feeling of the tenacity with which a person attains goals despite having hurdles and obstacles. This feature appeared when Participant 1 told about her nature:

"I have very strong willpower. If I have decided to do something I will do it whatever hurdles come in my way." 
This concept was reinforced by the statement given by Participant 6 :

"In one of my courses my assignment was rejected thrice but I didn't give up. I went to my professor one day and sat with him to understand where I was going wrong and when I understood the concept completely I resubmitted my assignment, which was approved then."

Participant 2 added:

"The libraries are replete with research studies conducted in the management and social science areas, however hardly any of these are ever read by industry practitioners. There is a lack of experiential learning in our subjects. But I am still determined to contribute to the research work."

An interesting quality of self-reliance arose during the discourse with the participants. The rigor with which participants improved their reading and writing skills is notable. Participant 2 expressed her accomplishment of being well-read and conversant with the domain she is working in and the savoir-faire with research methodologies:

"Doctorate means you have to be well-read. I have very good reading skills. I read a lot. The research requires lots of reading to understand the theories, methods, and domain of research. I am very well motivated to read, which helped me get so far."

The theme of problem-solving arose during 5 interviews. According to Benard (2004), problem-solving skills refer to analytical thinking and being resourceful even in adverse conditions. This was apparent in the form of social and academic integration of the participants while doing their dissertations and other assignments. Participant 1 explained when asked how she managed her obligations along with the job and studies:

"I am disciplined in the sense that I give time to the family and self when I don't have exams and submission and when I have those deadlines I sit and work." 
This statement explains how she managed the triple role of being a housewife, an employee, and a student. She had set priorities in life to fulfill the responsibilities accordingly. The problem-solving skills are reflected in the creativity of managing all the accountabilities simultaneously.

Another theme that was common and shared by the majority of participants was autonomy, which implies working independently and be assertive in all situations. This theme was also verified when Participant 4 said:

"The people at this stage are so mean that they make friends only if they feel you can benefit them. The ultimate way to get through this program is to work on your own."

Sense of purpose emerged as another theme. People having sense of purpose know the meaning of what they are doing and hence they are highly organized. They set goals and objectives and then strategize accordingly to achieve them. This concept arose when Participant 8 said:

\section{"I plan my things and strategize about how I would go next."}

Almost all the participants mentioned sense of purpose when they were asked about their career prospects. All the participants had clear goals about what level they wanted to achieve and how they have planned to go about it. Participant 2 said she wanted to be a microfinance consultant and that she was working on her thesis on the same topic to get the expertise on the subject area. 


\section{Figure 1}

Graphical Presentation of the Themes Contributing Towards the Academic Resilience

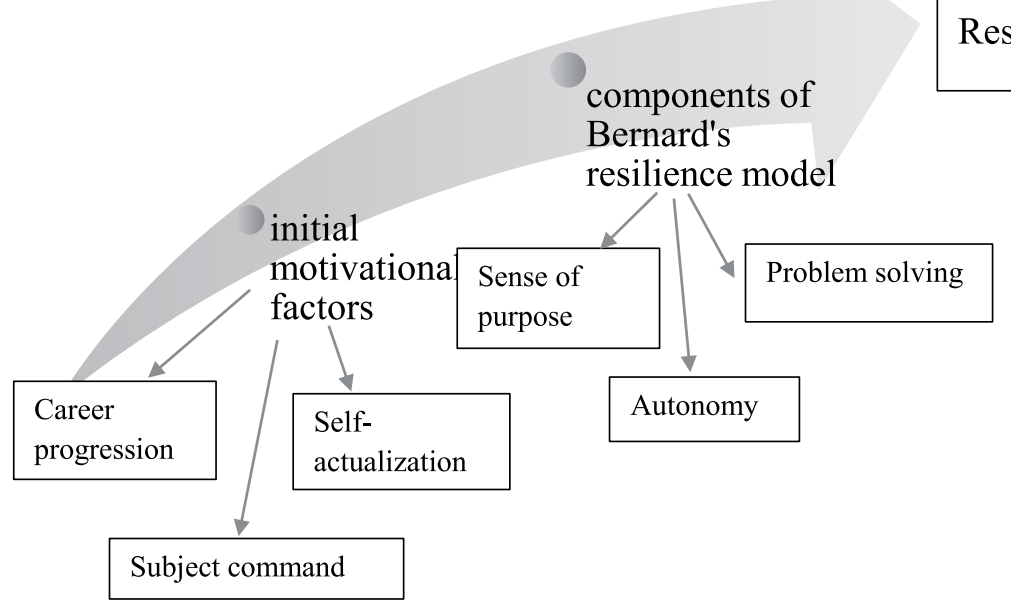

Academic

Resilience

\section{Discussion}

In this study, the initial motivational factors and the influence of individual characteristics that affect a candidate to pursue and then persist in a doctoral education were explored. There are several challenges and barriers inherent in the doctoral program, which are mainly associated with the extensive research required in the degree. Due to the complexity of this program, a candidate must have the persistent motivation to sustain and thrive in it. The findings of the current study explain that the initial motivation has a significant impact salient influence on the persistence level in the educational path. Since all the participants had a compelling and strong motive to embark upon the doctoral degree, their psychological effect on degree completion was substantial. The significant motives indicated for pursuing a doctoral degree were mainly career progression, a desire to increase the knowledge of the domain, and a need to prove oneself as a successful person in life (i.e., selfactualization). The identified motives were in line with the ones reported in various studies - for example, Brailsford (2010), Gill and Hoppe (2009), and Hymes et al. (2015). Further, the responses during the interviews explicitly described various hurdles and challenges along the way to degree completion. Inaccessibility of expert advisors, inadequate guidance, and the difficulty to manage the dual workload (of job and doctoral research) were found mutual to all of them. These findings are consistent with those of Ezebilo (2012) who studied the challenges and hurdles 
faced by doctoral students and the strategies to cope with those barriers. We also looked for the attributes that are aligned with Benard's (2004) theory of resiliency.

When the participants were asked about their competencies that helped them to progress through the program, they identified their time management, planning, and strategizing skills, which can be summed up to conclude that the individual is highly organized and disciplined in one's endeavors. These traits point towards a 'sense of purpose'. During the interviews, the theme of self-reliance and depending on oneself to control the environment has also emerged. This concept of 'autonomy' was supported by Participant 7's statement: "I don't need friends; I am comfortable working alone." One of the important characteristics identified by participants was their ongoing spirit. The participants were so tenacious that they completed a task no matter what hurdles came their way. This attribute is identified as 'self-determination'. The problem-solving skills were also identified during the interviews. However, the social competence trait identified by Holder (2007) was viable for students who were the faculty members of the university (as they become socialized with the teachers, they are motivated to complete their degree and publish their research papers), but this was not found to be the case with non-faculty participants.

\section{Conclusion and Recommendations}

A doctorate is the highest academic degree; doctors are considered as scientists and technologists containing marvelous capabilities to conceive novel ideas and solutions for the sustainable development of society and economy by availing their knowledge, wisdom, and analytic to technical skills. Hence, this article aimed to discover the factors that contribute to increasing the persistence level among doctoral students, which leads them to complete their degrees in light of the perceived challenges of the doctoral program.

The research findings could act as a lens through which the faculty and the administrators of the doctoral program could discern and comprehend the issues faced by the students. Thus, they can make changes in the policies to promote the retention of the students and introduce mentoring programs to adequately address the problems, and also design an efficient recruitment program to select the candidates with prospective potential. The counseling centers or clinics should be set up in the universities to help students for their mental well-being and develop 
academic resilience in them. Additionally, the aspect of experiential learning can be introduced in Pakistan like the developing countries where the liaison between the industry and education sector provides the platform to research to solve the practical problems faced by the industry. Availability of massive open online courses (MOOCs) for free to discounted bases also helps students in the acquisition of new skills including doctoral students (Qureshi, 2019). Further, through the findings of this research, prospective doctoral students might be better able to understand the challenges they may experience and to devise the strategies necessary to remain persistent in their doctoral journey.

\section{References}

Akram, M. (2019). Psychological Well-being of University Teachers in Pakistan. Journal of Education and Educational Development, 6(2), 235.

Alva, S. A., \& Padilla, A. M. (1995). Academic invulnerability among Mexican Americans: A conceptual framework. The Journal of Educational Issues of Language Minority Students, 15, 27-48.

Bashir, S., Syed, S. \& Qureshi, J. A. (2017). Philosophical and Methodological Aspects of Mixed-Methods Research: A Review of the Academic Literature. Journal of Independent Studies and Research, 15(1), 32-50.

Benard, B. (2004). Resiliency: What we have learned. WestEd.

Berelson, B. (1960). Graduate education in the United States. McGraw Hill.

Bowen, W., \& Rudenstine, N. (1992). In pursuit of the PhD. Princeton University Press.

Brailsford, I. (2010). Motives and aspirations for doctoral study: Career, personal, and interpersonal factors in the decision to embark on a history doctorate. International Journal of Doctoral Studies, 5, 15-28.

Burton, E. (2020). Factors Leading Educators to Pursue a Doctorate Degree to Meet Professional Development Needs. International Journal of Doctoral Studies, 15, 075-087.

Castro, V. Garcia, E. E, Cavazos, J., \& Castro, A.Y. (2011). The road to doctoral success and beyond. International Journal of Doctoral Studies, 6, 51-77.

Chamadia, S., \& Shahid, M. (2018). Skilling for the future: Evaluating post-reform status of "skilling pakistan" and identifying success factors for TVET improvement in the region. Journal of Technical Education and Training, 10(1), 47-58.

Churchill, H., \& Sanders, T. (2007). Getting your doctorate: An insiders'guide. Sage.

Clark, G. (2005). Reform in higher education in Pakistan. Education reform in Pakistan: Building for the future. Washington, DC: Woodrow Wilson Center for Scholars. 
Cochran, J. D., Campbell, S. M., Baker, H. M., \& Leeds, E. M. (2014). The role of student characteristics in predicting retention in online courses. Research in Higher Education, 55, 27-48.

Cresswell, J. W. (2007). Qualitative research design: Choosing among five approaches. Sage.

Deci, E., \& Ryan, R. (1985). Intrinsic motivation and self-determination in human behavior. Plenum Press

Dickerson, S. H., Byers, V. T., Smith, R. N., Hwang, E., Angrove, K. E., Chandler, J. I., . . . Onwuegbuzie, A. J. (2014). Survival strategies: Doctoral students' perceptions of challenges and coping methods. Library Faculty and Staff Publications, 15. Retrieved from http://scholarworks.sfasu.edu/libfacpub/15

Ezebilo, E. E. (2012). Challenges in postgraduate studies: Assessments by doctoral students in a Swedish University. Higher Education Studies, 2, 49-58.

Fuerth, K. M. (2008). Resiliency in academically successful Latina doctoral students: Implications for advocacy (Doctoral dissertation, University of South Florida, FL).

Garcia, L. A. (2014). Factors of Attrition in Cohort Doctoral Education: A Self Determination Theory Perspective.

Gawel, J. E. (1996). Herzberg's theory of motivation and Maslow's hierarchy of needs. Practical Assessment, Research, and Evaluation, 5(1), 11.

Gill, T. G., Hoppe, U. (2009). The business professional doctorate as an informing channel: A survey and analysis. International Journal of Doctoral Studies, 4, 27-57

Golde, C. M. (2005). The role of the department and discipline in doctoral student attrition: Lessons from four departments. Journal of Higher Education, 76, 669-700.

González, A.C. (2007). Surviving the doctorate and thriving as faculty: Latina junior faculty reflecting on their doctoral studies experiences. Equity \& Excellence in Education, 40, 291-300.

Halai, N. (2011). Becoming and being a doctoral supervisor in Pakistan: A lived experience. In V. Kumar \& A. Lee(Eds.), Doctoral education in international context: Connecting local, regional and global perspectives (pp.37-49). Serdang, Malaysia: Malaysia Press.

Hatch, J. A. (2002). Doing qualitative research in education settings. SUNY Press. Holder, B. (2007). An investigation of hope, academics, environment, and motivation as predictors of persistence in higher education online programs. The Internet and Higher Education, 10, 245-260.

Howard, S., \& Johnson, B. (2000). What makes the difference? Children and teachers talk about resilient outcomes for children 'at risk'. Educational 
Studies, 26, 321-337.

Hymes, C.E., Spicer, S., Hardy, E.A., Waddell, M., \& Hatcher, S.L. (2015) Midcourse corrections and life satisfaction in a sample of mid-career doctoral students. The Qualitative Report, 20, 1709-1722.

Linden, J., Ohlin, M., \& Brodin, E. M. (2013). Mentorship, supervision \& learning experience in Doctorate education. Studies in Higher Education, 38, 639662.

Marshall, C., \& Rossman, G. B. (1999). The "what" of the study: Building the conceptual framework. Designing Qualitative Research, 3, 21-54.

Masten, A. S., \& Coatsworth, J. D. (1998). The development of competence in favorable and unfavorable environments, American Psychologist, 53, 205220.

McMillan, J. H., \& Reed, D. F. (1994). At-risk students and resiliency: Factors contributing to academic success. The Clearing House, 67, 137-140.

Morales, E. E. (2008, January). The resilient mind: The psychology of academic resilience. The Educational Forum, 72, 152-167.

Moreno, M. D. C. C., \& Kollanus, S. (2013, October). On the motivations to enroll in doctoral studies in Computer Science-A comparison of PhD program models. In 2013 12th International Conference on Information Technology Based Higher Education and Training (ITHET) (pp. 1-8). IEEE.

Mujtaba, B. G., Scharff, M. M., Cavico, F. J., \& Mujtaba, M. G. (2008). Challenges and joys of earning a doctorate degree: Overcoming the "ABD" phenomenon. Research in Higher Education Journal, 1(1), 10-26.

Powell, S., \& Green, H. (2007). The doctorate worldwideMcGraw-Hill Education.

Pyhältö, K., Toom, A., Stubb, J., \& Lonka, K. (2012). Challenges of becoming a scholar: A study of doctoral students' problems and well-being. ISRN Education, 2012, 1-12.

Qureshi, J. A. (2019). Evolution and Advancement in Massive Open Online Courses (MOOC) to Revolutionize Education Sector via Disruptive Technology: The Case of Pakistan. Journal of Education and Educational Development, 6(2), 219-234.

Spaulding, L. S., \& Szapkiw, J. R. (2012). Hearing their voices: Factors doctoral candidates attribute to their persistence. International Journal of Doctoral Studies, 7, 199219.

Teowkul, K., Seributra, N. J., Sangkaworn, C., Jivasantikarn, C., Denvilai, S., \& Mujtaba, B. G. (2009). Motivational factors of graduate Thai students pursuing master and doctoral degrees in business. RU International Journal, 3(1), 25-56. 